\title{
An experimental study of kerosene combustion in a supersonic model combustor using effervescent atomization
}

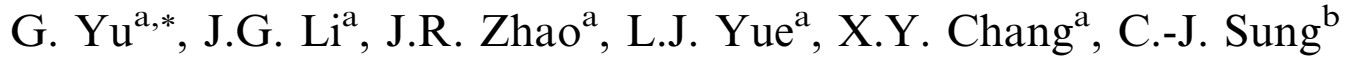 \\ a Institute of Mechanics, Chinese Academy of Sciences, Beijing 100080, PR China \\ ${ }^{\mathrm{b}}$ Department of Mechanical and Aerospace Engineering, Case Western Reserve University, Cleveland, OH 44106, USA
}

\begin{abstract}
Investigation of kerosene combustion in a Mach 2.5 flow was carried out using a model supersonic combustor with cross-section area of $51 \mathrm{~mm} \times 70 \mathrm{~mm}$ and different integrated fuel injector/flameholder cavity modules. Experiments with pure liquid atomization and with effervescent atomization were characterized and compared. Direct photography, Schlieren imaging, and planar laser induced fluorescence (PLIF) imaging of $\mathrm{OH}$ radical were utilized to examine the cavity characteristics and spray structure. Schlieren images illustrate the effectiveness of gas barbotage in facilitating atomization and the importance of secondary atomization when kerosene sprays interacting with a supersonic crossflow. OH PLIF images further substantiate our previous finding that there exists a local high-temperature radical pool within the cavity flameholder, and this radical pool plays a crucial role in promoting kerosene combustion in a supersonic combustor. Under the same operation conditions, comparison of the measured static pressure distributions along the combustor also shows that effervescent atomization generally leads to better combustion performance than the use of pure liquid atomization. Furthermore, the present results demonstrate that the cavity characteristics can be different in non-reacting and reacting supersonic flows. As such, the conventional definition of cavity characteristics based on non-reacting flows needs to be revised.

(C) 2004 The Combustion Institute. Published by Elsevier Inc. All rights reserved.
\end{abstract}

Keywords: Supersonic combustion; Effervescent atomization

\section{Introduction}

Curran [1] recently reviewed the scramjet technologies over the past 40 years. In this comprehensive review, two emerging scramjet applications were identified therein, namely hydrogen-fueled engines for access to space and

\footnotetext{
* Corresponding author. Fax: +8610 62561284

E-mail address: yugong@imech.ac.cn (G. Yu).
}

hydrocarbon-fueled engines for air-launched missiles [1]. For the latter, hydrocarbon fuels are attractive because they are easier and safer to handle than hydrogen [2]. However, one major difficulty associated with the use of hydrocarbon fuels is that their relatively long ignition delay times could be substantially larger than the residence time of gas flow within typical supersonic combustors. Moreover, quick vaporization prior to the mixing and combustion is crucial when using liquid hydrocarbons. In general, technology 
and scientific challenges towards the successful development of liquid hydrocarbon-fueled scramjets include: (1) a deeper fuel penetration into the air stream for better mixing; (2) generation of smaller liquid fuel droplets for faster evaporation; (3) a appropriate flame stabilization mechanism for piloting and sustaining combustion; and (4) a substantial reduction in drag losses associated with processes of mixing and flameholding.

In terms of recent supersonic combustor development, cavity-based fuel injector/flameholder configurations combined with effervescent atomization are of particular interest $[1,2]$. In the effervescent atomization mode, gas bubbles are introduced to the liquid fuel, leading to a turbulent two-phase flow that can improve the penetration and vaporization of the fuel jet spray. Arai and Schetz [3] and Lin et al. [4] employed the effervescent atomization technique to examine the spray structure in a supersonic crossflow. Their results showed that for high levels of barbotage the liquid breakup process occurs immediately after or even before the liquid is discharged due to the highly turbulent nature of this inhomogeneous two-phase flow and the rapid expansion caused by the high-pressure barbotage gas. Besides, the overall spray penetration height in the barbotage mode increases with increasing amount of barbotage gas. Mathur et al. [5] further demonstrated with JP-7 fuel that the aerating effect of the barbotage injection indeed enhances fuel/air mixing and combustion.

In our previous study [6], we have investigated kerosene combustion in a model supersonic combustor using pure liquid atomization and effervescent atomization with either air or hydrogen being the barbotage gas. The results showed that if a higher level of kerosene atomization can be achieved with gas barbotage, the overall burning of the kerosene in supersonic airflow could be enhanced, irrespective of what barbotage gas used. However, it has to be recognized that the extent of combustion enhancement strongly depends on the operation condition of effervescent atomization. In addition, by examining the surface color of the cavity floor, it was inferred that there exists a local high-temperature region, which would be the significant factor in promoting the ignition and the subsequent flameholding of the kerosene combustion.

It is noted that our previous investigation [6] on barbotaged kerosene jets have been conducted based on the measurements of some global properties, such as stagnation temperature, stagnation pressure, and static pressure. While the measured global properties have provided useful information, detailed characterizations of both spray structure and reaction zone would allow scrutiny at the next level of rigor. Therefore, the present study extends our previous efforts by utilizing non-intrusive optical techniques in the supersonic experiments, including Schlieren imaging and planar laser induced fluorescence (PLIF) of the key radical $\mathrm{OH}$.

The test facility and specifications of various optical diagnostics are presented in the next section, which is subsequently followed by results and discussion.

\section{Experimental specifications}

\subsection{Test facility}

The test facility consisted of a Mach 2.5 vitiated air supply system, a multi-purpose supersonic combustor, and liquid and gaseous fuels delivery systems. The facility was controlled by a computer and capable of supplying heated air at a range of stagnation temperature of 800 $2100 \mathrm{~K}$ and stagnation pressure of $0.7-1.3 \mathrm{MPa}$. The supersonic combustor had an entrance cross-section area of $51 \mathrm{~mm} \times 70 \mathrm{~mm}$. As shown in Fig. 1, the combustor was comprised of three sections, namely one nearly constant area section and two divergent sections. Integrated fuel injector/flameholder cavity modules were used for fuel injection and supersonic combustion experiments. Each cavity was of $12 \mathrm{~mm}$ in depth $(h=12 \mathrm{~mm})$ and of $45^{\circ}$ in aft ramp angle. Two cavity lengths $(L)$, defined as the distance from the cavity leading edge to the starting-point of the aft ramp, were studied and compared, namely $L=60$ and $88 \mathrm{~mm}$. For light access and observation, a pair of quartz windows, each of $46 \mathrm{~mm}$ in width and $124 \mathrm{~mm}$ in length, were installed on both sides of a combustor near the location of cavity module, as shown in Fig. 1. The entire test facility was mounted upright on a platform and could be translated laterally and vertically.

Kerosene was normally injected into the airflow either at $46 \mathrm{~mm}$ upstream of the cavity or at the cavity floor, while the pilot hydrogen was normally injected at $5 \mathrm{~mm}$ upstream of the cavity. Five equally spaced barbotage injectors with the same exit orifice diameter were distributed along the wall width of $70 \mathrm{~mm}$. Details of the effervescent atomization system employed herein have been documented in [6]. Figure 2 shows the barbotage atomizer system with a single injector. The inset of Fig. 2 further delineates the design of the present effervescent atomizer, which consisted of an internal tube with a diameter of $1.5 \mathrm{~mm}$ and an external tube with a diameter of $4 \mathrm{~mm}$. The inner tube was for kerosene passage, while the barbotage gas flowed through the annular gap between the tubes. The distance between the end of the internal tube and the exit orifice was $15 \mathrm{~mm}$. Two different atomizers were used, with orifice diameters (denoted as D in Fig. 2) being 0.5 and $0.8 \mathrm{~mm}$. Air barbotage was used in the present study. 


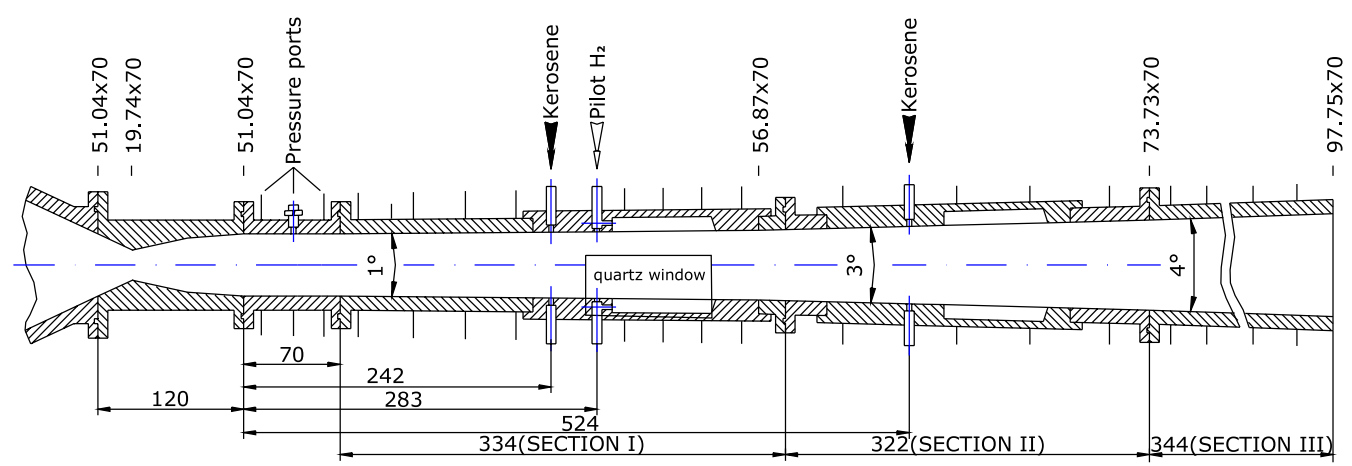

Fig. 1. Schematic of kerosene/pilot hydrogen supersonic model combustor. All length dimensions are in mm.

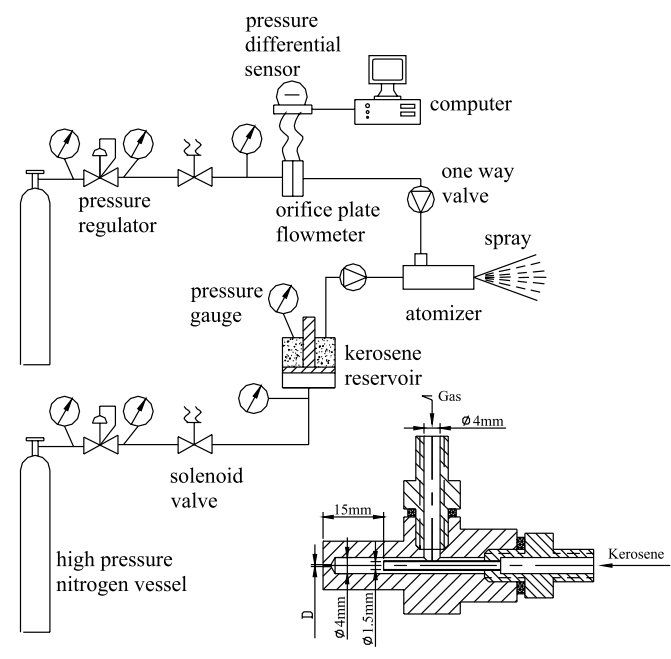

Fig. 2. Schematic of barbotage atomizer system.

Kerosene was stored in a cylinder and pumped through a piston at a desired pressurized state. The piston was driven by pressurized nitrogen that was regulated through nitrogen supply, regulators, pressure sensor, and two solenoid valves for quick turn on/off. The barbotage gas was supplied through a high-pressure gas cylinder controlled by regulators, solenoid valve, pressure sensor, orifice plate of $1.2 \mathrm{~mm}$ diameter, and a one-way valve. Kerosene flow rate was measured by the actual amount of kerosene released from the kerosene cylinder divided by the time elapsed. A calibrated orifice plate measured flow rate of the barbotage gas. The pressure difference between upstream and downstream of the orifice was determined by a differential pressure transmission sensor (Model CYB-1151, Beijing Zhong Hang Machinery and Electron Technology), with measuring error being within $2 \%$.

Static pressures were measured along the axial direction of the flow-path. Motorola MPX2200 0-
$0.5 \mathrm{MPa}$ pressure sensors were used to detect the static pressure signal. The uncertainty associated with the static pressure measurement was estimated to be within $2 \%$.

\subsection{Visualization of effervescent atomization}

Visualization of the global spray plume was carried out using a digital video camcorder (SONY TRV-20) with a proper backlighting for illumination. Moreover, pure liquid or effervescent atomization in the supersonic combustor was visualized via Schlieren images, in which the non-uniform density gradient caused by the spray dispersion in supersonic flow field was illustrated. In the present Schlieren system, the reflecting mirror has a diameter of $150 \mathrm{~mm}$ and a focusing length $(f)$ of $1500 \mathrm{~mm}$. The slit width was set to be $0.15 \mathrm{~mm}$, and the knife-edge was arranged to have a displacement normal to the stream-path. Continuous light source using quartz tungsten halogen lamp and a pulsed arc light discharged at high voltage were utilized for obtaining time averaged and instantaneous images of the spray structure, respectively. A conventional camera with $4 \mathrm{~ms}$ exposure time was used to record time averaged Schlieren images, while the instantaneous images were recorded using 667 Polaroid films.

\subsection{Characterization of combustion field}

PLIF imaging of $\mathrm{OH}$ was applied for the characterization of supersonic combustion in the cavity region. A Spectra Physics GCR290-30 $\mathrm{Nd}$ :YAG laser $(30 \mathrm{~Hz})$ was frequency-doubled to $532 \mathrm{~nm}(0.8 \mathrm{~J} /$ pulse $)$, which was then used to pump a Lumonics HD-500 dye laser. The doubled-frequency output of the dye laser was of $283.642 \mathrm{~nm}, 5 \mathrm{~mJ} /$ pulse, $5 \mathrm{~ns}$ pulse width, and $100 \mathrm{MHz}$ band width, which was used to excite the $Q_{1}(8)$ branch in $\mathrm{X}^{2} \Pi-\mathrm{A}^{2} \sum^{+}(0,1)$ band of $\mathrm{OH}$ radical. A cylindrical lens $(f=5 \mathrm{~mm})$ combined with a spherical lens $(f=400 \mathrm{~mm})$ convert 
the beam into an expanding sheet, which was approximately $12 \mathrm{~cm}$ wide and $0.4 \mathrm{~mm}$ thick. The $\mathrm{OH}$ fluorescence signal was collected by a Princeton Instruments ICCD 1152MG-E $(1024 \times 298$ pixels $)$ camera along with a Nikon UV-Nikker F/4.5 lens $(f=105 \mathrm{~mm})$. Additionally, three $2 \mathrm{~mm}$ thick Schott UG-11 filters were used to block the visible and infrared luminosity resulting from kerosene/air combustion, while a WG305 filter was used to block the laser scattering. As a comparison with the OH PLIF images, direct images of supersonic combustion within the cavity were also taken by using a digital video camcorder with a neutral density filter.

\subsection{Experiment procedure}

The typical tests lasted $7 \mathrm{~s}$ using a pre-programmed sequencer. In the heater, the major gases (air, oxygen, and hydrogen) were released $1 \mathrm{~s}$ after a spark ignited the pilot mixture of air and hydrogen. It generally took about $1.5 \mathrm{~s}$ to reach a steady state and achieve the required temperature and pressure. Once the steady Mach 2.5 airflow was established (at $\sim 2.475 \mathrm{~s}$ ), the pilot hydrogen was injected and subsequently self-ignited if the condition was adequate. It took another $2 \mathrm{~s}$ to achieve a steady burning for the given pilot hydrogen and airflow. Kerosene was then injected at $\sim 4.5 \mathrm{~s}$. Once the pilot hydrogen flame ignited the kerosene, the overall kerosene burning would be sustained even after turning off the pilot hydrogen.

\section{Results and discussion}

\subsection{Schlieren images}

Kerosene spray visualization in the Mach 2.5 model combustor was accomplished via Schlieren images. First set of six Schlieren images shown in Fig. 3 compares the spray structures of kerosene jets with and without air barbotage in a supersonic crossflow, at two different injection pressures $(2.3$ and $3.5 \mathrm{MPa})$. The flow direction is upward and the local static conditions were of $430 \mathrm{~K}$ and $0.043 \mathrm{MPa}$. Here the cavity flameholder modules were removed and replaced by flat plates. For all cases in Fig. 3, the atomizer of $0.8 \mathrm{~mm}$ orifice diameter was used. The values of barbotage gas/liquid mass ratio (GLMR) and kerosene jet-to-air stream momentum ratio $\left(q_{L}\right)$ $q_{A}$ ) are also specified in Fig. 3. Moreover, the time averaged images are shown in Figs. 3A-D, while Figs. $3 \mathrm{E}$ and $\mathrm{F}$ are the instantaneous images. These Schlieren results are consistent with the visualization of Arai and Schetz [3] and Lin et al. [4]. In particular, the kerosene spray was severely bent by the Mach 2.5 crossflow, and the bow shock ahead of the spray was also evident.
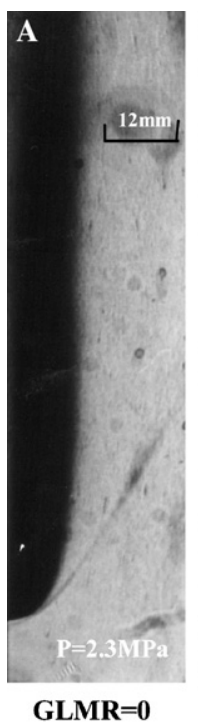

$q_{L} / q_{A}=7.01$

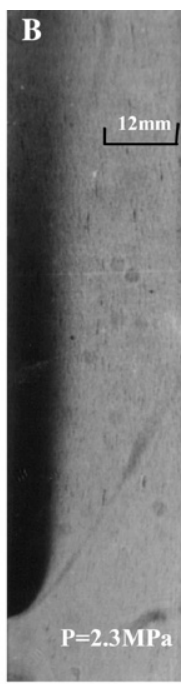

GLMR $=\mathbf{0 . 0 2}$

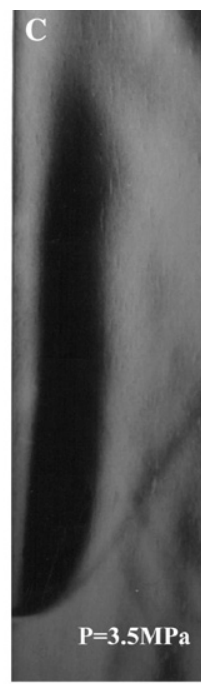

GLMR $=0$

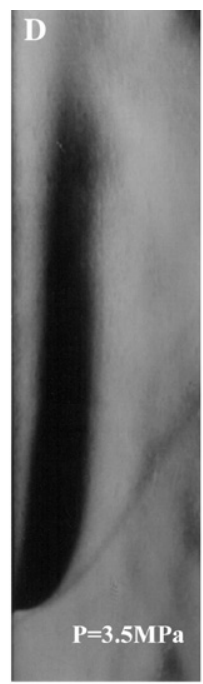

GLMR $=0.02$

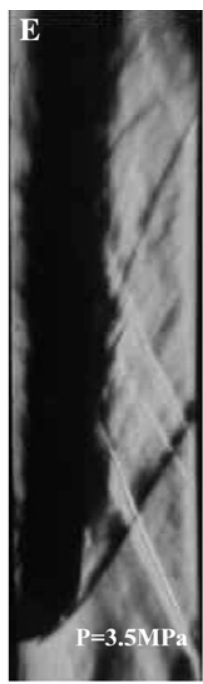

GLMR=0

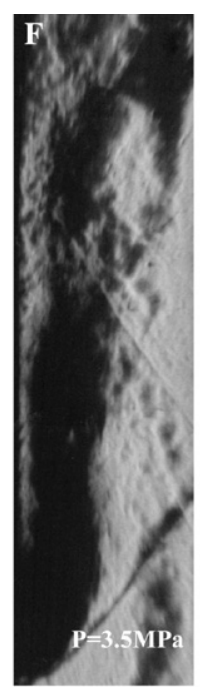

GLMR $=\mathbf{0 . 0 1 7}$

Air Mach Number $=2.5$, Static Pressure $=0.043 \mathrm{MPa}$, Static Temperature $=430 \mathrm{~K}$

Fig. 3. Schlieren images of kerosene spray structure with and without barbotage in a supersonic combustor. $P$ denotes the injection pressure. (A-D) Time averaged images. (E-F) Instantaneous images. 
It was further found that the penetration correlation developed by Kush and Schetz [7] for a pure liquid jet: $h_{\mathrm{o}} / d_{\mathrm{o}}=6 q_{\mathrm{o}}^{0.49}$, where $h_{\mathrm{o}}$ is the penetration height, $d_{\mathrm{o}}$ the orifice diameter, and $q_{\mathrm{o}}$ the momentum ratio, still approximately holds in the present effervescent cases. This may be due to the smallness of GLMR so that its effect on the jet momentum is small. Lin et al. [4] has shown that gas barbotage indeed increases the penetration height. In practice, however, because of the strong interaction between liquid and barbotage gas, it would not be straightforward to maintain the amount of liquid injection constant while varying the value of GLMR. Therefore, effervescent atomization may not have a strong effect on penetration height, unless the injection pressure is changed substantially.

Furthermore, the momentum ratio of kerosene jet-to-air stream plays an important role in determining the penetration height. For a given airflow, the penetration height increases with increasing jet momentum. A recent review on effervescent atomization by Sovani et al. [8] illustrated that a two-phase flow through a nozzle chokes at a significantly lower velocity than that at which a single-phase flow would choke. Hence, a two-phase flow, such as effervescent atomization, will experience a steep pressure jump at the nozzle exit, even at relatively low flow velocities and low injection pressures. As a result, the jet momentum with effervescent atomization is expected to be smaller than that without gas barbotage. This is consistent with the present findings. Our experimental results therefore suggest that the enhancement of kerosene combustion with effervescent atomization is mainly caused by the smaller droplets generated.
Second set of six Schlieren images shown in Fig. 4 is for the kerosene spray passing a cavity of length-to-depth ratio $L / h=7.3$ in the supersonic combustor, with and without barbotage gas. Here, the orifice diameter of atomizer was $0.8 \mathrm{~mm}$ and the injection pressure was kept constant at $3.5 \mathrm{MPa}$. The images of spray injected at a location just ahead of cavity are shown in Figs. 4A and B, while for Figs. 4C and D kerosene was injected at $46 \mathrm{~mm}$ upstream of the cavity. Figures $4 \mathrm{~A}-\mathrm{D}$ clearly demonstrate the characteristics of an open cavity for non-reacting flows (cf. $[9,10])$. When kerosene is injected at the cavity floor, the spray structure becomes rather complex, as shown in Figs. 4E and F. For the pure liquid atomization mode (Fig. 4E), a solid cylindrical liquid column was observed near the injector exit. Fig. 4F illustrates that this column was enlarged with gas barbotage. Moreover, for the effervescent atomization mode there existed additional interference structures ahead of the spray, although the causes for those structures are not yet clear. One possible mechanism could be due to the interaction of spray and the low-speed recirculation zone within the cavity. Furthermore, it is expected that the secondary atomization phenomenon would be important here, which is a result of the interaction between spray and supersonic stream such that larger droplets could be shattered into smaller ones by the impact of supersonic flow. Quantitative measurement of mean droplet diameter is needed to elucidate such a phenomenon. Overall, gas barbotage was observed to facilitate the droplet breakup process, which may explain our previous findings that combustion efficiency is increased with the aid of effervescent atomization [6].

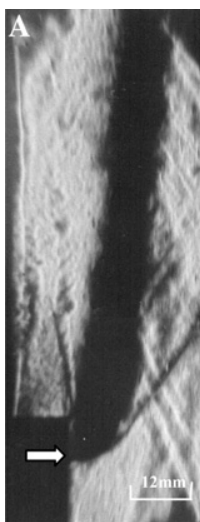

GLMR $=0$

$q_{L} / q_{A}=10.74$

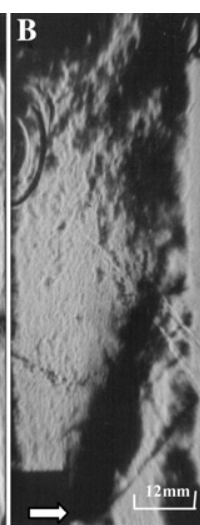

GLMR $=0.021$

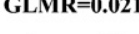

$q_{L} / q_{A}=10.42$

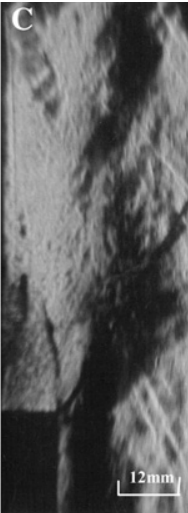

GLMR $=0$

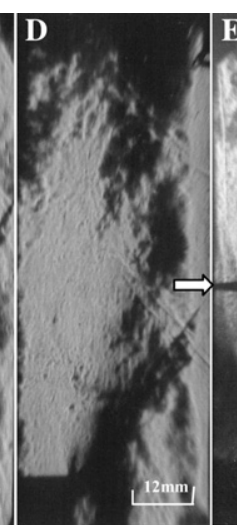

GLMR $=0.0226$

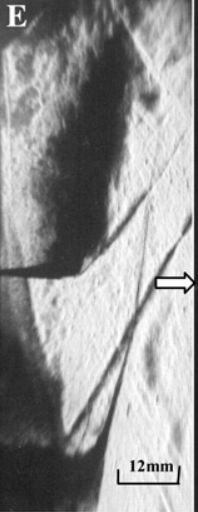

GLMR $=0$

$q_{L} / q_{A}=9.4$

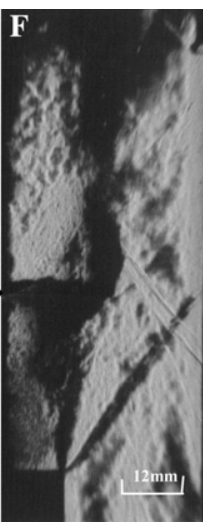

GLMR $=\mathbf{0 . 0 2 1 5}$

$q_{L} / q_{A}=10.11$

Air Mach Number $=2.5$, Static Pressure $=0.043 \mathrm{MPa}$, Static Temperature $=430 \mathrm{~K}, \mathrm{~L} / \mathrm{h}=7.3$

Fig. 4. Schlieren images of kerosene spray structure passing a cavity of length-to-depth ratio $L / h=7.3$ in a supersonic combustor, with and without barbotage. Injection pressure is fixed at $3.5 \mathrm{MPa}$. 
A

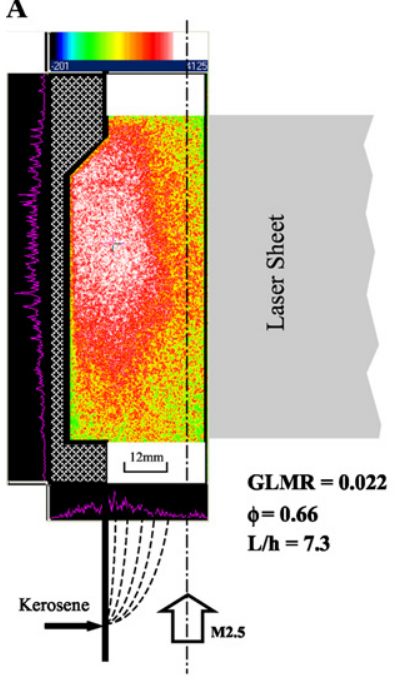

B

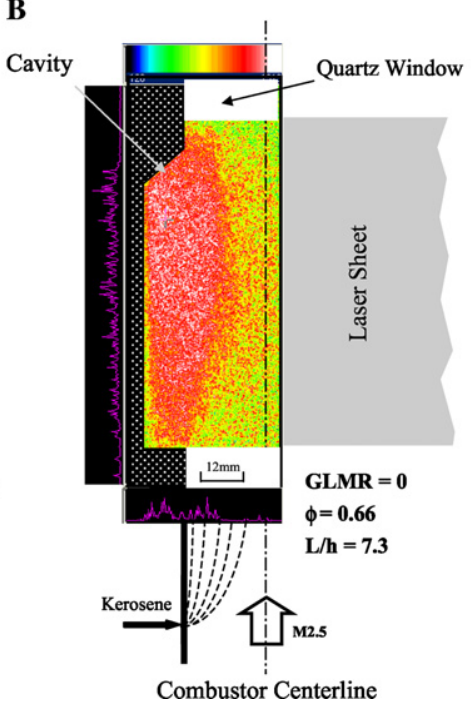

C

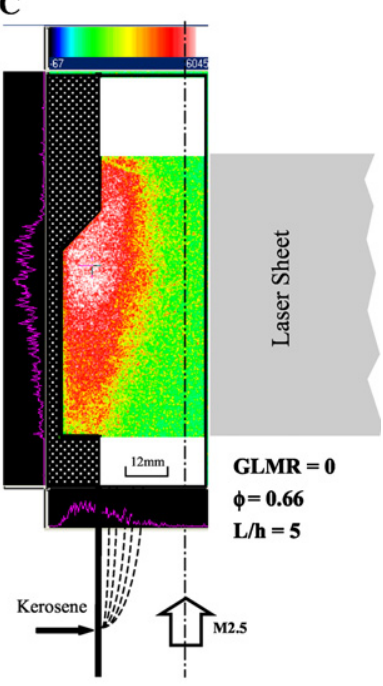

Fig. 5. OH PLIF images of kerosene spray combustion within the cavity.

\subsection{PLIF Images}

PLIF measurements of $\mathrm{OH}$ were carried out to characterize the kerosene combustion in supersonic combustor as well as to examine the dominant flameholding mechanism of the integrated cavity module. The readers are referred to, e.g., $[1,9,10]$, for pioneering work on flameholding cavities. Figures 5A and B compare the cases with and without air barbotage, respectively. The atomizer used here has an orifice diameter of $0.5 \mathrm{~mm}$. The running conditions and the corresponding static pressure profiles in combustor are shown in Fig. 6. In Fig. 5, the global fuel/air equivalence ratio $(\phi)$ was kept constant at 0.66 . The mass flow rates of kerosene and pilot hydrogen were 66 and $7.5 \mathrm{~g} /$ $\mathrm{s}$, respectively. While the cavity length-to-depth ratio $(L / h)$ is 7.3 for Figs. $5 \mathrm{~A}$ and $\mathrm{B}$, the $L / h$ value is 5 for Fig. 5C. Since the quartz windows of $46 \mathrm{~mm} \times 124 \mathrm{~mm}$ are not large enough to cover the entire combustor cross-section, only half of domain is shown herein.

Figure 5 clearly demonstrates the existence of $\mathrm{OH}$ radical pool within the cavity, which is close to the aft ramp. Since $\mathrm{OH}$ is indicative of reaction zone, it is seen that combustion is initiated within the cavity, which serves as a flameholding source. The promoting effect of gas barbotage on kerosene combustion is evident by comparing Figs. 5A and B. Comparison of Figs. 5B and C also signifies the differences in $\mathrm{OH}$ distribution due to different $L / h$ values. Especially, there appears no combustion along the combustor centerline for the case of $L / h=5$.

It is also of interest to compare the static pressure profiles shown in Fig. 6 for the cases with
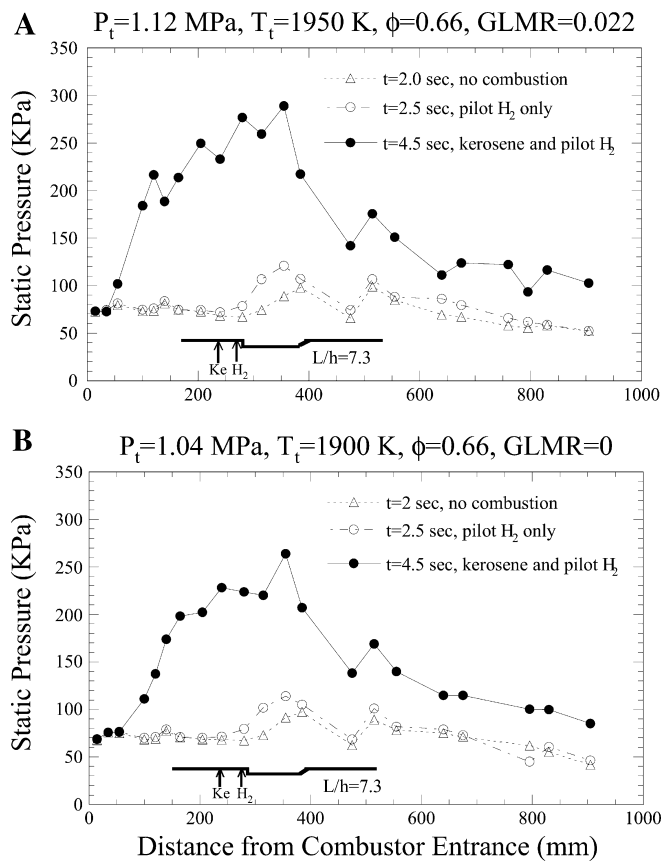

Fig. 6. Comparison of static pressure profiles in the axial direction: (A) effervescent atomization and (B) pure liquid atomization. $P_{\mathrm{t}}$ and $T_{\mathrm{t}}$ represent stagnation pressure and stagnation temperature, respectively.

and without gas barbotage. The relative position of the cavity module is also sketched as a reference. We first note that the stagnation conditions of Figs. 6A and $\mathrm{B}$ are similar. As a result, the resulting supersonic non-reacting flow fields are 
essentially the same. With small amount of pilot hydrogen injection, the peak pressure increases slightly. It is noted that pilot hydrogen alone does not lead to substantial pressure rise within the combustor. In addition, the static pressure profile is shown to be reproducible. After steady combustion of kerosene was sustained, Fig. 6 shows that the location of cavity flameholder coincides quite well with the regime of major pressure rise, indicating that the dominant heat release must take place within the cavity flameholder regime. It is further seen that the peak pressure yielded by effervescent atomization (Fig. 6A) is higher than that obtained using pure liquid atomization (Fig. 6B). Hence, under the same operation conditions, results generally show that effervescent atomization can enhance fuelair mixing, facilitate the generation of fine droplets for fast evaporation, and generate more heat release to promote the global burning.

Figure 7 further compares the direct photograph and OH PLIF image for kerosene combustion in cavity. The Schlieren image of the nonreacting kerosene spray without gas barbotage is also shown as a comparison. For the given cavity of $L / h=7.3$, the non-reacting Schlieren image (Fig. 7A) indicates the nature of open cavity in that the shear layer shed from the leading edge of cavity moves across the cavity without impinging on the cavity floor $[9,10]$. With combustion, Figs. 7B and $\mathrm{C}$ demonstrate the change in cavity characteristics. Especially, the cavity becomes approximately a closed cavity because the spray is now deflected towards the bottom floor of the cavity, even starting from the very beginning of the cavity. It is reasonable to expect that the increases in local temperature and pressure due to combustion would significantly affect the supersonic flow field. Therefore, the conventional definition of the cavity characteristics based on the non-reacting flow requires revision for the cases with combustion.

Furthermore, Figs. $7 \mathrm{~B}$ and $\mathrm{C}$ show that the flame luminous zone corresponds well with the location of radical pool. By examining the surface color of the cavity floor, we have reported previously $[6,11]$ that there exists a localized high-temperature zone in the stagnation region near the aft slanted wall because of the severe change in the surface color therein. The present OH PLIF results substantiate the existence of a high-temperature reaction zone and its role in promoting initiation as well as flameholding of kerosene combustion.
A

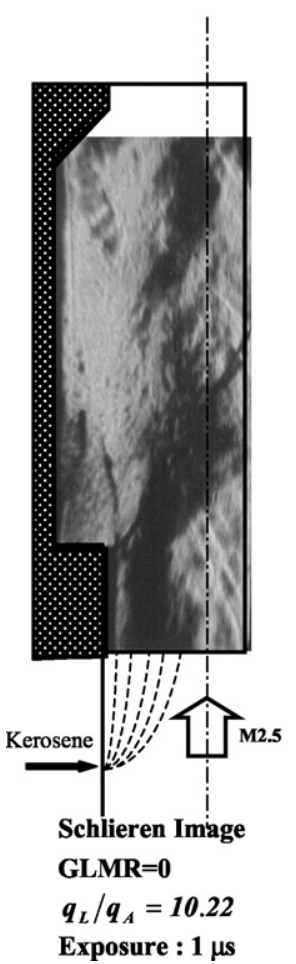

B

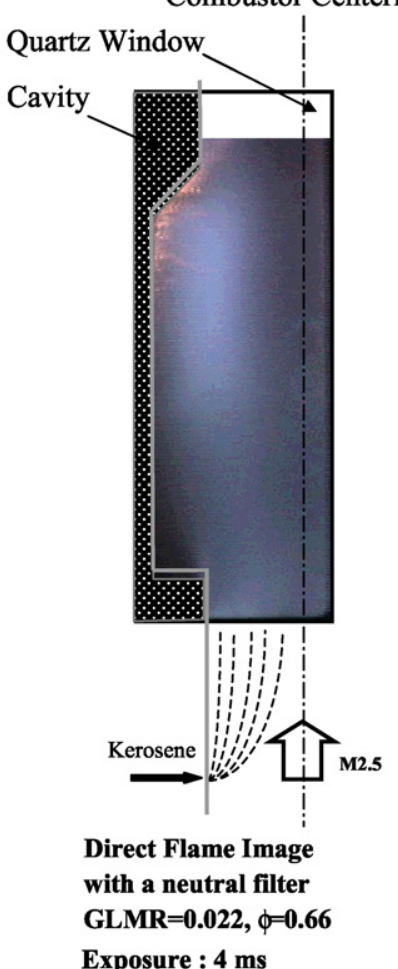

C

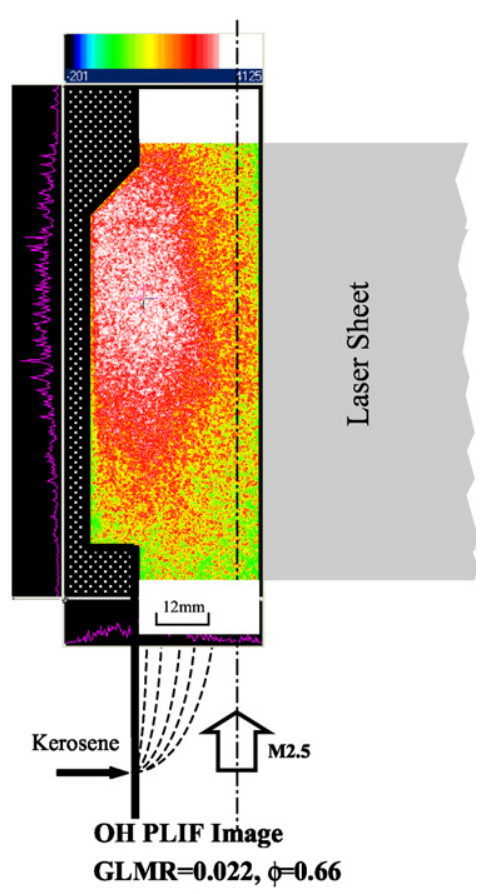

30 Pulses Accumulate

Fig. 7. Comparison of Schlieren image, direct flame image, and OH PLIF image. 


\section{Summary}

Schlieren imaging and OH PLIF were utilized to characterize effervescent atomization under different conditions. Spray structures with and without gas barbotage were investigated and compared in a Mach 2.5 combustor with a cross-sectional area of $51 \mathrm{~mm} \times 70 \mathrm{~mm}$. The interactions of barbotaged kerosene spray and a cavity-based flameholder in a supersonic model combustor were of particular interest.

Schlieren images of kerosene spray interacting with cavity in the non-reacting supersonic crossflow suggest the importance of secondary atomization. Additionally, gas barbotage was observed to result in smaller kerosene droplets, and hence is expected to yield higher combustion efficiency. However, it was found that gas barbotage might not have a strong effect on the penetration height, which is mainly dependent on the injection pressure. Further study in this regard is warranted.

For a cavity of length-to-depth ratio being 7.3, Schlieren images demonstrated that under non-reacting conditions it exhibited an open cavity characteristics because the shear layer moves across the cavity without impinging on the cavity floor. Once kerosene combustion is initiated, the abrupt increases in temperature and pressure lead to the change in cavity characteristics. OH PLIF images and flame luminosity observation clearly revealed the existence of a localized high-temperature reaction zone within the cavity. In view of the spray flow being deflected towards the cavity floor, the cavity becomes a closed one with combustion. A revised definition of cavity characteristics for reacting flows is certainly needed. Furthermore, the present OH PLIF images substantiate our previous findings that a local hightemperature radical pool in the cavity is crucial in promoting the initiation and the subsequent flameholding of the kerosene combustion in a supersonic combustor.

\section{Acknowledgments}

The work at the Chinese Academy of Sciences was supported by the National Natural Science Foundation of China under contract 1023060. C.J.S. was supported by the Case School of Engineering through the Case Alumni Association. The authors acknowledge Mr. Z. Zhao for the assistance in mechanical drawing. We also thank Mr. D.X. Qian and Mr. Y. Li. for their technical support of this work.

\section{References}

[1] E.T. Curran, J. Propul. Power 17 (6) (2001) 1138-1148.

[2] O.A. Powell, J.T. Edwards, R.B. Norris, K.E. Numbers, J. Propul. Power 17 (6) (2001) 1170-1176.

[3] T. Arai, J.A. Schetz, J. Propul. Power 10 (3) (1994) 382-386.

[4] K.-C. Lin, K.A. Kirkendall, P.J. Kennedy, T.A. Jackson, AIAA Paper (1999) 99-2374.

[5] T. Mathur, K.-C. Lin, P.J. Kennedy, M.R. Gruber, J. Donbar, T. Jackson, F. Billig, AIAA Paper (2000) 2000-3581.

[6] G. Yu, J.G. Li, X.Y. Chang, L.H. Chen, C.-J. Sung, J. Propul. Power 19 (5) (2003) 885-893.

[7] E.A. Kush, J.A. Schetz, AIAA J. 11 (9) (1973) 1223-1224

[8] S.D. Sovani, P.E. Sojka, A.H. Lefebvre, Prog. Energy Combust. Sci. 27 (2001) 483-521.

[9] M.R. Gruber, K.-Y. Hsu, J. Propul. Power 17 (1) (2001) 146-153.

[10] A. Ben-Yakar, R.K. Hanson, J. Propul. Power 17 (4) (2001) 869-877.

[11] G. Yu, J.G. Li, X.Y. Chang, L.H. Chen, C.-J. Sung, J. Propul. Power 17 (6) (2001) 1263-1272. 